\title{
Influence of Streamer-to-Glow Transition on NO Removal by Inductive Energy Storage Pulse Generator
}

\author{
Koichi Takaki
}

Iwate University

Japan

\section{Introduction}

Huge amounts of air pollutants like carbon monoxide, unburned hydrocarbons, nitrogen oxides (NOx), and particulate matter have been released into the atmosphere by various sources such as coal, oil, and natural gas-burning electric power generating plants, motor vehicles, diesel engine exhaust, paper mills, metal and chemical production plants, etc., over the last several decades. These pollutants are the main cause of acid rain, urban smog, and respiratory organ disease (Chang, 2001). For pollutants emitted from motor vehicle, the exhaust of gasoline engines is cleaned effectively with the three-way catalyst. However, for diesel and lean burn engines, the three-way-catalyst does not work because the high oxygen content in the exhaust gases prevents the reduction of nitrogen oxide (NO) (Clements et al., 1989).

Dry NOx removal technology is one of the conventional processes which may provide a potential solution for such problems (Eliasson and Kogelschatz, 1991). A non-thermal plasma process using a pulse streamer corona discharge is particularly attractive for this purpose (Namihira et al., 2000). During the past decade, numerous studies on this process have been conducted using a diesel engine exhaust gas and/or a simulated gas (Hackam \& Akiyama, 2000). Although encouraging results have been obtained from the experiments, it is urgent to design a whole removal system compact enough for vehicle application.

Two methods for storing energy are employed in high-power pulse generators: capacitive and inductive storages. When the energy is stored in capacitors, the energy is transferred to a load through closing devices, e.g., high-current nanosecond switches. If the energy is stored in an inductive circuit with current, opening switch is used to transfer energy to a load (Rukin, 1999). For short-pulsed high voltage generation with high impedance load, inductive energy storage (IES) system is more adequate than capacitive energy storage system, if appropriate opening switches are available (Jiang et al., 2007).

High-voltage nanosecond pulse generators, in which high-voltage semiconductor diodes are employed for interrupting currents stored as inductive energy, have been developed (Rukin, 1999). The generators using the high-voltage diodes as semiconductor opening switch (SOS) have an all-solid-state switching system and therefore, combine high pulse repetition rate, stability of the output parameters and long lifetime (Grekhov \& Mesyats, 2002). SOS pulse generators operating at various institutions demonstrated their high reliability during 
applied research work connected with the pumping of gas lasers (Baksht et al., 2002), ionization of air with a corona discharge (Yalandin, et al., 2002, Cathey, et al., 2007), generation of radical species with a atmospheric pressure glow discharge (Takaki, et al., 2005), and generation of high-power microwave (Bushlyakov et al., 2006).

The streamer discharges driven by a pulsed power generator can dissociate oxygen molecules to atomic oxygen radicals with high-energy efficiency because of low-conductive current loss (Fukawa et al., 2008). The IES pulsed power generator using SOS diodes is particularly attractive for this purpose because the whole system can be compact, lightweight and driven at high repetition rate. However, a discharge produced by the IES pulsed power generator transients from streamer to glow when the energy stored in the capacitor still remains after the energy transfer from a capacitor to an inductor at opening the SOS diodes (Grekhov \& Mesyats, 2002). As the results, the energy efficiency for gas treatment using non-thermal plasma is affected by the streamer-to-glow transition (Takaki et al., 2007). In here, NO removal using a co-axial type non-thermal plasma reactor driven by an IES pulsed power generator is described. The influence of streamer-to-glow transition on NO removal in the non-thermal plasma reactor is also described.

\section{Experimental setup}

Figure 1(a) shows the schematics of the experimental circuit. The IES pulsed power generator consists of a primary energy storage capacitor $C$, a closing switch SW, a secondary energy storage inductor $L$, and an opening switch. The circuit current flows to the LC circuit governed by the following equation after closing the switch SW (Robiscoe et al., 1998):

$$
\begin{gathered}
i=\frac{V_{0}}{\omega_{0} L} e^{-\frac{R}{2 L} t} \sin \omega_{0} t, \\
\omega_{0}=\sqrt{\frac{1}{L C}-\left(\frac{R}{2 L}\right)^{2}},
\end{gathered}
$$

where $t$ is the time from the activation of the closing switch, $V_{0}$ is the charged voltage, $L$ is the inductance of the energy storage inductor, $C$ is the capacitance of the primary energy storage capacitor, and $R$ is the circuit resistance $(R<4 L / C)$. When SOS diodes are used as an opening switch as shown in Figure 1(a), the circuit current flows through the SOS diodes as a forward-pumping current during a half period $T_{F} \approx \pi \sqrt{L C}$ of LC oscillation (Yalandin et al., 2000). After the current direction reverses with LC oscillation, the reverse current is injected into the SOS during the period $T_{R}$. After the injection phase $T_{R}$, the circuit current is interrupted by a short duration $T_{\mathrm{O}}$. With the current interrupted by the SOS, a high-voltage pulse is produced as follows:

$$
V_{\text {out }}=V_{0}-\frac{1}{C} \int i d t-L \frac{d i}{d t}-R i \approx-L \frac{d i}{d t},
$$

as shown in Fig. 1(b). This pulse voltage can be applied to a load as a short nanosecond pulse (Takaki et al., 2005, Rukin, 1999, Yankelevich \& Pokryvailo, 2002). 


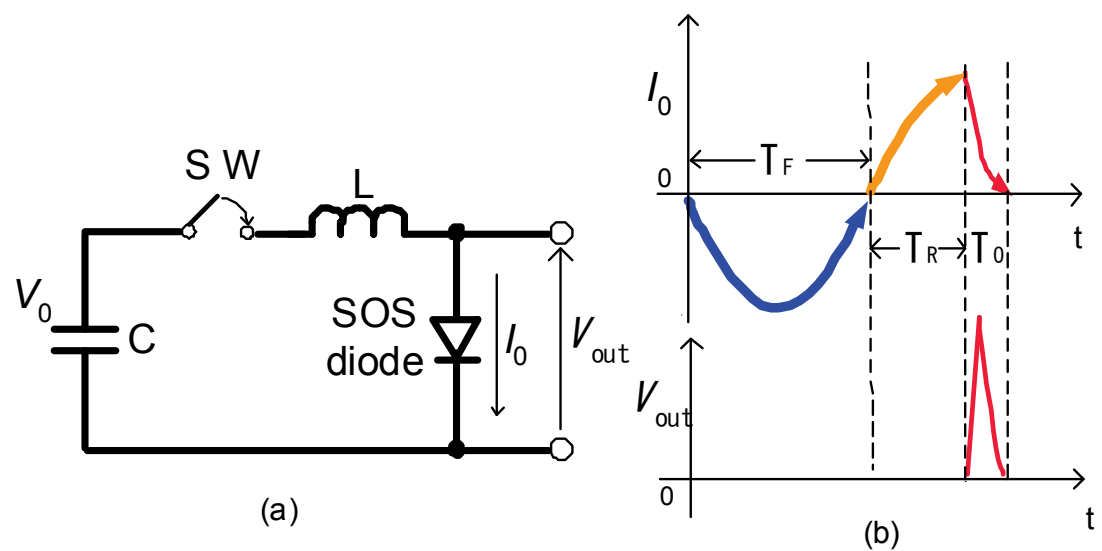

Fig. 1. Schematic of an inductive energy storage pulse power generator with semiconductor opening switch: (a) equivalent circuit; (b) circuit current and output voltage.

Fast reverse recovery diodes VMI K100UF (Voltage Multipliers, Inc., $10 \mathrm{kV}$ maximum voltage, 100 A maximum current, $T_{R}=100$ ns) were employed as SOS diodes, i.e., a semiconductor opening switch. K100UF diodes were connected in 5 series and 4 parallel to decrease the circuit inductance and to increase capable forward pumping current and reversed voltage (400 A maximum current, $50 \mathrm{kV}$ maximum voltage). The capacitance of the primary energy storage capacitor $C$ and the inductance of the secondary energy storage inductor $L$ were changed in range from 0.12 to $4.2 \mathrm{nF}$ and from 4.8 to $18.5 \mu \mathrm{F}$, respectively, as shown in Table 1. The charging voltages of the capacitor $C$ were $-20 \mathrm{kV}$ for conditions $1-3$ and $-12 \mathrm{kV}$ for condition 4 . The pulse repetition rate was changed to control the input energy in the reactor. The current and voltage were measured with Pearson 2878 current transformers (0.1 V/A sensitivity, 400 A maximum current, 5 ns rise time) and Tektronix high-voltage P6015A probe (40 kV peak voltage, 4 ns rise time), respectively. The signals stored in a Tektronix TDS3054B digitizing oscilloscope $(500 \mathrm{MHz}$ band width, $5 \mathrm{GS} / \mathrm{s}$ sampling rate) was transmitted to a computer through a LAN cable for calculating the energy consumed in reactor.

\begin{tabular}{|c|c|c|c|c|}
\hline Condition & $\# 1$ & $\# 2$ & $\# 3$ & $\# 4$ \\
\hline \hline$C[\mathrm{nF}]$ & 0.12 & 0.23 & 0.48 & 4.2 \\
\hline$L[\mu \mathrm{H}]$ & 18.5 & 10.5 & 4.8 & 12.6 \\
\hline$T_{F}[\mathrm{~ns}]$ & 203 & 205 & 224 & 876 \\
\hline$T_{R}[\mathrm{~ns}]$ & 67 & 68 & 69 & 102 \\
\hline
\end{tabular}

Table 1. Forward and reversed pumping time of SOS diodes for various circuit parameters.

Figure 2 shows a schematic of the experimental set-up using the pulse streamer discharge reactor. The simulated gas was diluted $\mathrm{NO}$ with nitrogen and oxygen mixed with ratio of 9:1. The co-axial plasma reactor consists of a $1 \mathrm{~mm} \phi$ tungsten wire and a copper cylinder 


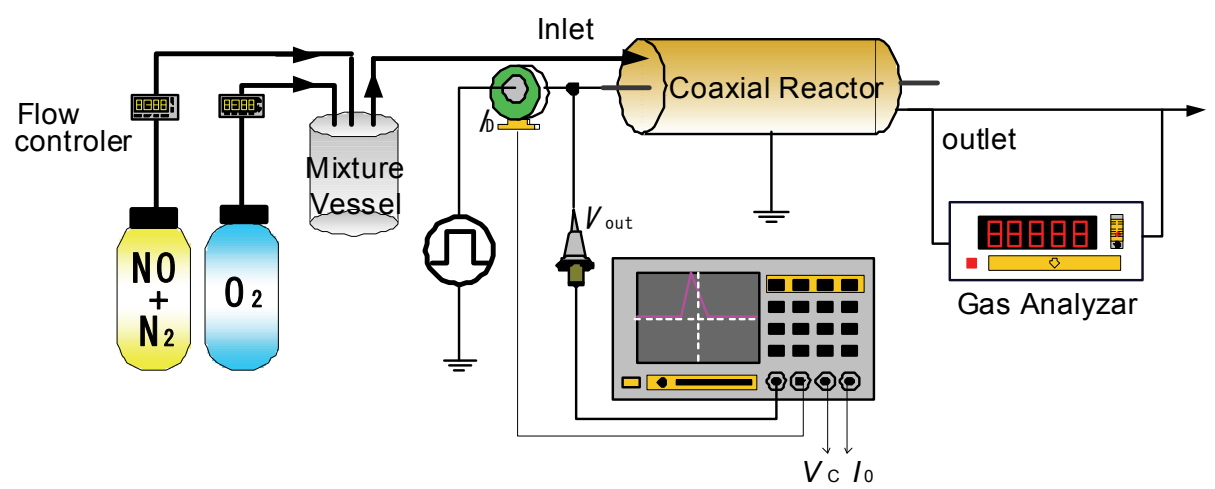

Fig. 2. Experimental setup for NO removal from simulated exhaust gas using a corona discharge reactor driven by an IES pulse power generator.

with an inner diameter of $20 \mathrm{~mm}$. The length of the reactor is $300 \mathrm{~mm}$, which corresponds to $94 \mathrm{cc}$ in volume. The initial concentration of NO gas was controlled to $200 \mathrm{ppm}$ using a mass flow controller. The flow rate of the simulated gas was changed from 2 to $4 \mathrm{~L} / \mathrm{min}$. The NO and $\mathrm{NO}_{2}$ gases were analyzed by Best Sokki BCL-511 gas analyzer.

\section{Results and discussion}

\subsection{Pulse power circuit behavior}

Figure 3 shows typical waveforms of circuit current $I_{0}$, capacitor voltage $V_{\mathrm{C}}$, and output voltage $V_{\text {out }}$ without connecting to the load at $C=0.48 \mathrm{nF}$ and $L=4.8 \mu \mathrm{H}$. The charging voltage $V_{0}$ of the capacitor $\mathrm{C}$ is $-10 \mathrm{kV}$. "Time $=0$ " means the time after closing the gap switch SW. The circuit current $I_{0}$ starts to flow after closing the gap switch SW with LC oscillation. The diode forward-pumping period $T_{\mathrm{F}}$, i.e., a half period of LC oscillation, is $210 \mathrm{~ns}$, and the peak of the forward-pumping current is $67 \mathrm{~A}$. After the current direction reverses with LC oscillation, the reverse current is injected into the SOS during a $70 \mathrm{~ns}$ period $T_{\mathrm{R}}$. After the 70 ns injection phase $T_{R}$, the circuit current is interrupted for $25 \mathrm{~ns}$ duration $T_{\mathrm{O}}$. During this phase, the 50 A reversed current is interrupted for $25 \mathrm{~ns}$. The output voltage increases rapidly and has a maximum voltage of $22 \mathrm{kV}$, which corresponds to 2.2 of an amplification factor, i.e. corresponds to the ratio of the maximum output voltage to the charging voltage $V_{0}$. The pulse width of the output voltage is $25 \mathrm{~ns}$ in FWHM (full-width at half-maximum). The total inductance of the circuit is the summation of the secondary energy storage inductor and a circuit loop inductance. The total circuit inductance can be roughly estimated using the equation $T_{F} \approx \pi \sqrt{L C}$ and is calculated to be $9.6 \mu \mathrm{H}$ using a 210 ns half period of LC oscillation. This inductance and rapid current interruption produces a high voltage pulse expressed by Equation (3).

Table 1 shows the periods of a forward-pumping current $T_{\mathrm{F}}$ and the periods of a reverse current of the diodes $T_{\mathrm{R}}$ for various circuit conditions. The period $T_{\mathrm{F}}$ has approximately same values at around 200 ns (203, 205, and 224 ns for conditions 1, 2, and 3, respectively) for all three different conditions. The period $T_{\mathrm{F}}$ can be predicted as a half cycle of LC oscillation and was calculated to be 146, 154, and $150 \mathrm{~ns}$ using values of $C$ and $L$ of the conditions 1,2 , and 3 , respectively. The measured period $T_{\mathrm{F}}$ shows a larger value than those 


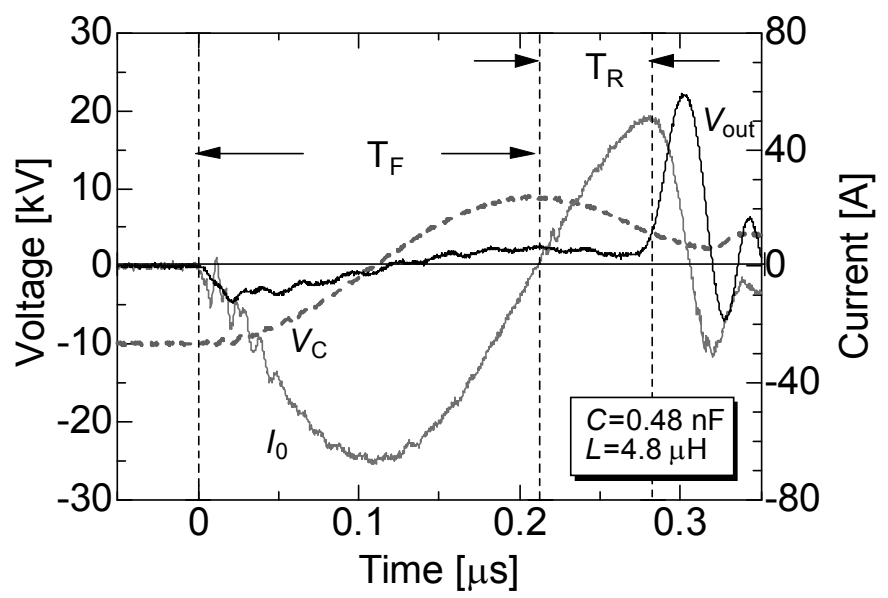

Fig. 3. Typical waveforms of circuit current $I_{0}$, capacitor voltage $V_{C}$, and output voltage $V_{\text {out }}$ without connection to the load at $C=0.48 \mathrm{nF}, L=4.8 \mu \mathrm{H}$ and $V_{0}=-10 \mathrm{kV}$.

calculated by the result of a stray inductance of the circuit. The reverse current period $T_{R}$ has approximately the same values for different circuit conditions in the same forward current period. However, the value of $T_{\mathrm{R}}$ is around $70 \mathrm{~ns}$ which is $70 \%$ of the rated period of $100 \mathrm{~ns}$. The values of $L$ and $C$ in condition 4 were chosen to increase the forward-current period $T_{\mathrm{F}}$ as $\pi \sqrt{L C}=723 \mathrm{~ns}$. The obtained period of $T_{\mathrm{R}}$ is $102 \mathrm{~ns}$, which agreed well with the rated period of $100 \mathrm{~ns}$.

Figure 4 shows the typical time-dependency of the discharge current $I_{\text {load, }}$, the circuit current $I_{0}$, the reactor voltage $V_{\text {out }}$ and the voltage of the primary energy storage capacitor $V_{\mathrm{C}}$ with connection of the pulsed power generator to the reactor. The circuit condition is chosen as $C=0.68 \mathrm{nF}$ and $L=1.4 \mu \mathrm{H}$. The charging voltage $V_{0}$ of the capacitor is set to be $-20 \mathrm{kV}$. The discharge current $I_{\text {load }}$ can be divided by two parts; displacement current at the early part of the current and a discharge current as the sharp peak. The peak value of the discharge current is around $100 \mathrm{~A}$. The voltage of the capacitor $V_{C}$ is almost zero when the pulse voltage is produced and applied to the reactor. This result indicates the energy stored in the capacitor is almost released through LC oscillation.

Figure 4 also shows time-dependency of energy stored in the secondary energy storage inductor $E_{\mathrm{L}}$, energy stored in the primary energy storage capacitor $E_{\mathrm{C}}$, energy loss in the SOS diodes $E_{\mathrm{SOS}}$ and energy consumed in the reactor $E_{\text {load. }}$. The energy stored in the capacitor is transferred to the inductor in the period of first quarter cycle of the LC oscillation. After that, the energy stored in the inductor is transferred back to the capacitor in next quarter cycle. The energy of $16 \mathrm{~mJ}$ is consumed in the SOS in the period of LC half cycle because of the resistive component of the SOS diodes. The total energy transfer from the primary energy storage capacitor to the reactor is around $20 \%$ under the circuit condition. The energy transfer efficiency changes by changing circuit parameter as reported in the reference (Takaki et al., 2007). The energy transfer efficiency increases to $40 \%$ by decreasing circuit current from 200 to $50 \mathrm{~A}$ in peak value because the energy loss in the SOS decreases with decreasing current through the SOS diodes. 


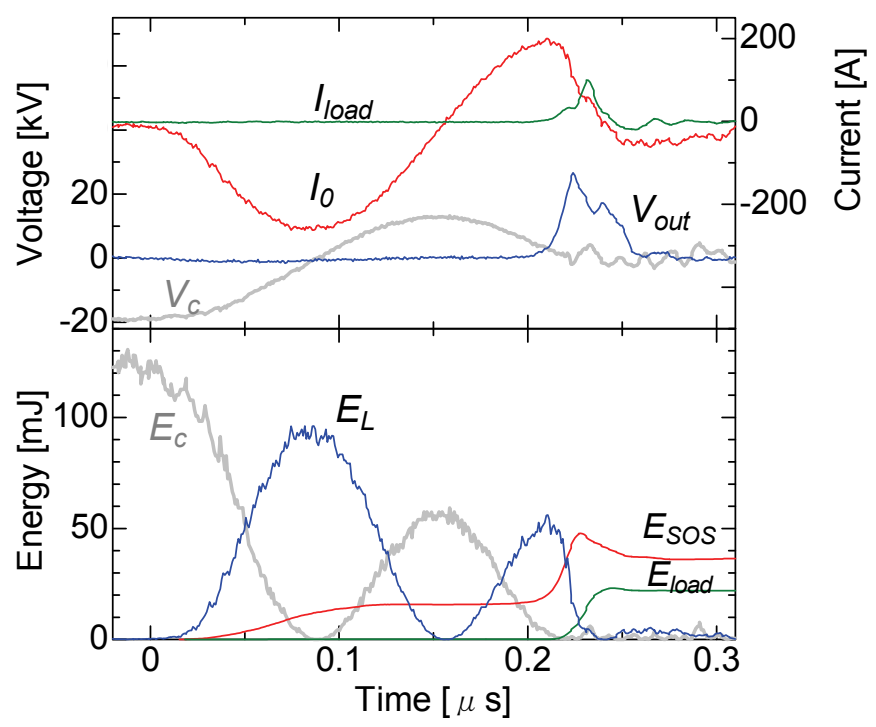

Fig. 4. Typical time-dependency of the discharge current $I_{\text {load }}$, the circuit current $I_{0}$, the reactor voltage $V_{\text {out }}$ and energy consumed in SOS, $E_{\mathrm{SOS}}$ and in the reactor $E_{\text {load }}$ at $C=0.68 \mathrm{nF}$, $L=1.4 \mu \mathrm{H}$ and $V_{\mathrm{C} 0}=-20 \mathrm{kV}$. $E_{\mathrm{C}}$ and $E_{\mathrm{L}}$ mean energies stored in the capacitor and the inductor, respectively.

Figure 5 shows the time dependence of the discharge current, the voltage between the electrodes, and the energy consumed for different circuit conditions. The energy consumed was calculated based on a multiplied value of the discharge current and the voltage (Takaki et al., 2000). The peak voltages between the electrodes were 19, 25, $27 \mathrm{kV}$ for conditions 1, 2, and 3, respectively. The peak current also increased from 32 to $54 \mathrm{~A}$ with an increase in the capacitance $C$ from 0.12 to $0.48 \mathrm{pF}$. The energies consumed in the discharge are $9,13,19 \mathrm{~mJ}$ for the circuit conditions 1,2, and 3, respectively. These values correspond to 39, 28, and $20 \%$ of the primary energy obtained by $0.5 C V_{0}{ }^{2}$, where $V_{0}$ is the charging voltage of the storage capacitor $\mathrm{C}$.

Figure 6 shows the waveforms of the discharge current, the voltage between the electrodes, and the energy consumed for circuit condition 4 . The time transient of circuit condition 2 is also shown in Fig. 6 for the comparison of different circuit conditions. The peak voltage and current obtained were $25 \mathrm{kV}$ and $62 \mathrm{~A}$, respectively. The waveforms of the discharge current and voltage have a long decay time compared to the cases of the conditions 1 to 3 as shown in Fig. 5. The time constant of the current decay is approximately $300 \mathrm{~ns}$. The time constant can be expressed as $R_{\mathrm{d}} \times C$, where $R_{\mathrm{d}}$ represents an equivalent resistance of the discharge. The equivalent resistance $R_{\mathrm{d}}$ is $70 \Omega$ using the capacitance $4.2 \mathrm{nF}$ as the value of $C$. This longer discharge current decay may indicate that a glow discharge is generated with the remaining electrical charges in the storage capacitor (K. Takaki et al., 2005). The voltage between the electrodes after the diodes interrupt the circuit current still remains around 11.5 $\mathrm{kV}$. This voltage corresponds to $48 \mu \mathrm{C}$ of the remaining charge in a storage capacitor. The total energy consumed is around $125 \mathrm{~mJ}$ which consists of $14 \mathrm{~mJ}$ in energy consumption by the pulse streamer discharge (at 73 ns from applying voltage, just prior to a quasi-stable 
phase) and $111 \mathrm{~mJ}$ by the quasi-stable glow discharge (=125 - $14 \mathrm{~mJ})$. The $14 \mathrm{~mJ}$ energy consumed by the streamer discharge is similar to the values obtained under the circuit conditions 1 to 3 as shown in Fig. 5.

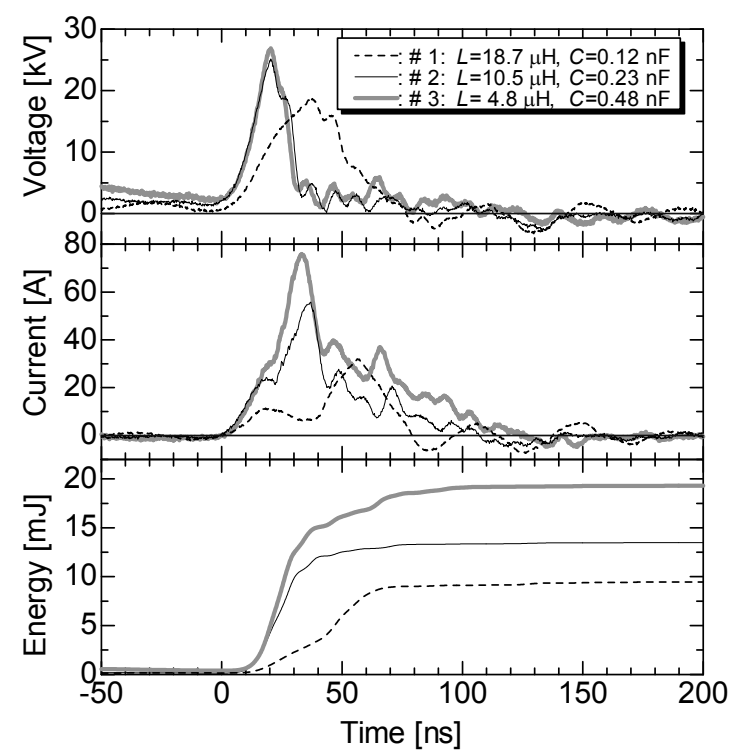

Fig. 5. Waveforms of applied voltage, discharge current, and energy consumed in the reactor for three different circuit conditions.

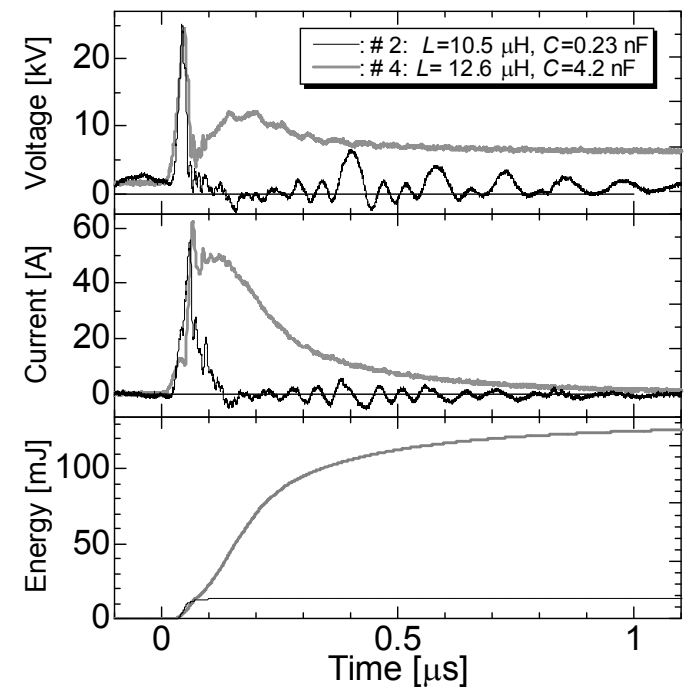

Fig. 6. Waveforms of applied voltage, discharge current, and energy consumed in the reactor at $4.2 \mathrm{nF}$ capacitance. 


\subsection{NO removal efficiency}

Figure 7 shows the NO removal efficiency as a function of the pulse repetition rate for two different gas flow rates and various circuit conditions. The charging voltages of the primary storage capacitor are maintained at around $25 \mathrm{kV}$ of the output voltage and are set to be $-20 \mathrm{kV}$ for conditions 1 to 3 and $-12 \mathrm{kV}$ for circuit condition 4 . The pulse repetition rate was controlled by the amplitude of charging current to the primary capacitor. NO removal increases with an increase in the pulse repetition rate for all cases. $\mathrm{NO}$ removal also increases with decreasing gas flow rate from 4 to $2 \mathrm{~L} / \mathrm{min}$. In all cases, $\mathrm{NO}_{x}\left(=\mathrm{NO}+\mathrm{NO}_{2}\right)$ removal was found to be lower than $10 \%$ by additional measurement using the $\mathrm{NO}_{\mathrm{x}}$ analyzer (Best Sokki BCL-511). This indicates that the NO removal is mainly due to oxidization of $\mathrm{NO}$ to $\mathrm{NO}_{2}$. The oxidation reactions can be written as follows:

$$
\begin{gathered}
\mathrm{NO}+\mathrm{O}_{3} \rightarrow \mathrm{NO}_{2}+\mathrm{O}_{2}, \\
\mathrm{NO}+\mathrm{O}+\mathrm{M} \rightarrow \mathrm{NO}_{2}+\mathrm{M},
\end{gathered}
$$

where $\mathrm{M}$ indicates ambient gas. The rate coefficient of reaction (4) $k_{\mathrm{NO} 2}$ is reported to be $1.7 \times 10^{-14} \mathrm{~cm}^{3} \mathrm{~s}^{-1}$ at 27 centigrade degree (Hill et al., 1988, Lowke and Morrow, 1995). The oxidation rate is expressed as $k_{\mathrm{NO} 2}[\mathrm{NO}]\left[\mathrm{O}_{3}\right]$, where $[\mathrm{NO}]$ and $\left[\mathrm{O}_{3}\right]$ indicate concentrations of $\mathrm{NO}$ and ozone, $\mathrm{O}_{3}$, respectively. The ozone is generated with the reaction between an oxygen molecule and an atom of oxygen which is mainly generated via energetic electron collision with the oxygen molecule. The reaction is expressed as follows;

$$
\begin{gathered}
\mathrm{e}+\mathrm{O}_{2} \rightarrow 2 \mathrm{O}+\mathrm{e}, \\
\mathrm{O}+\mathrm{O}_{2}+\mathrm{M} \rightarrow \mathrm{O}_{3}+\mathrm{M} .
\end{gathered}
$$

where $\mathrm{M}$ indicates ambient gas. The rate coefficient of the reaction (7) $k_{\mathrm{O} 3}$ is $6.3 \times 10^{-34} \mathrm{~cm}^{-6} \mathrm{~s}^{-1}$ at $300 \mathrm{~K}$ (Vikharev et al., 1993, Chang et al., 1991).

Some researchers employed input energy density (specific energy density; SED) to evaluate scale-up of NO removal yield (Hackam \& Akiyama, 2000, Penetrante et al., 1995).

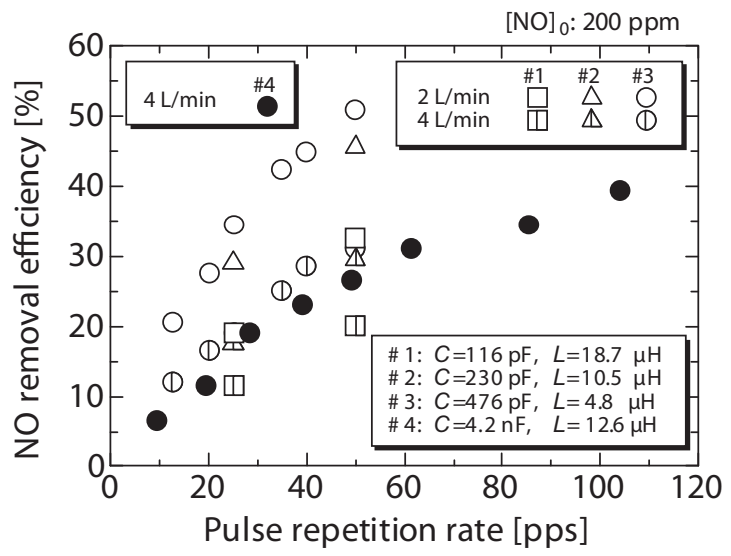

Fig. 7. Dependence of NO removal efficiency on pulse repetition rate for various gas flow rates and circuit parameters. 


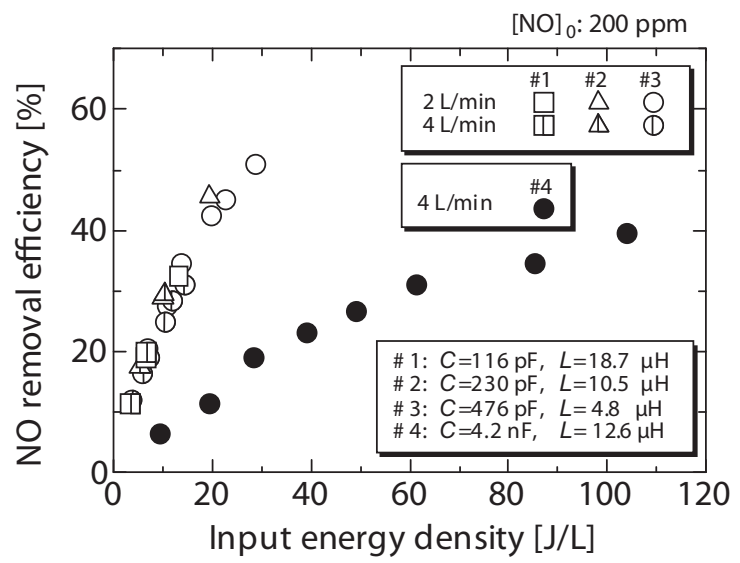

Fig. 8. Dependence of NO removal efficiency on the energy density for various circuit conditions.

Figure 8 shows the NO removal efficiency as a function of input energy density in the reactor for various circuit conditions. The input energy density is determined by the following equation,

$$
S E D=\frac{\text { Input electric power }}{\text { Gas flow rate }}=\frac{60 \cdot U \cdot f}{q}[\mathrm{~J} / \mathrm{L}]
$$

where $U$ means energy consumed in the reactor per one pulse of applied voltage obtained, as shown in Figs. 5 and 6. $f$ and $q$ are the pulse repetition rate [Hz] and the gas flow rate [L/min.], respectively. $1[\mathrm{~J} / \mathrm{L}]$ corresponds to $3.6\left[\mathrm{Wh} / \mathrm{m}^{3}\right]$. NO removal increases with input energy density. NO removal values of conditions 1 to 3 have similar values, whereas the NO removal value of condition 4 is much lower than those of other conditions. This result indicates that the primary energy storage capacitor $C$ and the secondary energy storage inductor $L$ must be set at $T_{F} / 2 \approx T_{R} \quad(\approx 100 \mathrm{~ns})$ for higher NO removal with lower energy input. When the values of $C$ and $L$ are set at $T_{F} / 2<<T_{R}$, the peak voltage of the pulsed power generator has a lower value owing to the lower $d i / d t$ value (Takaki \& Akiyama, 1992). When the $C$ and $L$ values are set at $T_{F} / 2 \gg T_{R}$, where the quasi-stable discharge (glow mode) is generated after the pulse streamer discharge. Another reason of the difference between NO removal for conditions 1 to 3 and condition 4 may be due to difference of the charging voltage for the primary energy storage capacitor. The voltages were $-12 \mathrm{kV}$ for conditions 1 to 3 and $-20 \mathrm{kV}$ for condition 4 . However, this difference is considered to only slightly affect the NO removal during the streamer mode because the peak voltage and the discharge current have slight differences between condition 2 and condition 4 as shown in Fig. 6.

Figure 9 shows the energy efficiency of NO removal as a function of the NO removal rate for various circuit conditions. The energy efficiency of NO removal is determined by the following equation, 


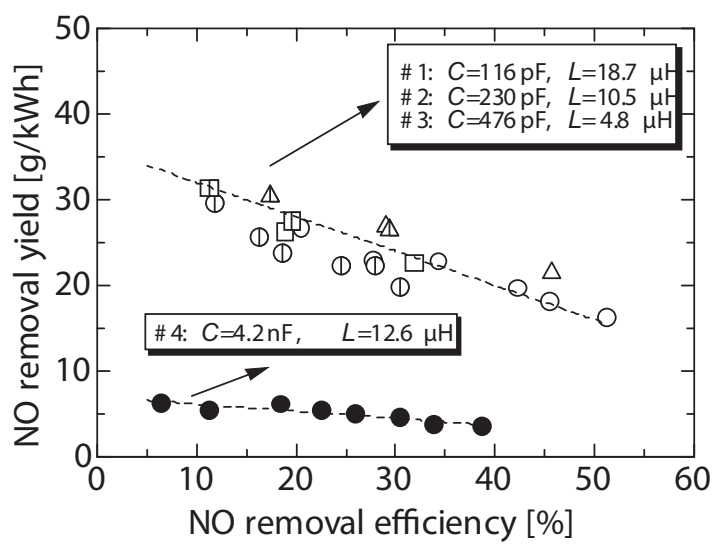

Fig. 9. Dependence of NO removal energy efficiency on NO removal for various circuit conditions.

$$
\eta=\frac{60 \cdot q \cdot \Delta[\mathrm{NO}] \cdot M}{N \cdot P} \times 10^{3}[\mathrm{~g} / \mathrm{kWh}]
$$

where $\Delta[\mathrm{NO}]$ is the NO removal [ppm], $M$ is the NO molecular weight (=30 g), $N$ is the molar volume $(=22.4 \mathrm{~L})$, and $P$ is the power consumed in the reactor $(=U \times f[\mathrm{~W}])$. The energy efficiencies of conditions 1 to 3 have similar values around $25 \mathrm{~g} / \mathrm{kWh}$ at $30 \%$ of NO removal. However, the energy efficiency of condition 4 is much lower than that of other circuit conditions at $5 \mathrm{~g} / \mathrm{kWh}$. The NO removal energy efficiency of $25 \mathrm{~g} / \mathrm{kWh}$ is similar order of magnitude with a pulse corona or pulsed streamer plasma reactor (Hackam \& Akiyama, 2000, Dinelli et al., 1990, Amirov et al., 1993). However, well-optimized pulse streamer plasma reactors show higher energy efficiency than present system (Namihira et al., 2000). For example, Yankelevich et al. (2006) reported NO removal energy efficiency of $30 \mathrm{~g} / \mathrm{kWh}$ for $30 \%$ of NO removal at $430 \mathrm{ppm}$ initial NO concentration in diesel engine exhaust (around $12.5 \% \mathrm{O}_{2}$ in the gas mixture). More optimization of present system is required to improve its efficiency.

For condition 4, the current waveform of the pulse driven glow discharge as shown in Fig. 6 can be divided into three parts: displacement current, streamer discharge current, and glow discharge current (Takaki et al., 2000). In the present experimental condition, the displacement current and the streamer discharge current appear around $40 \mathrm{~ns}$ and $65 \mathrm{~ns}$ after opening the switch diodes, as shown in Fig. 6. The glow discharge appears around 80 ns after opening the switch and is sustained about $1 \mu \mathrm{s}$. The glow discharge voltage after 200 ns from opening the switch is $10 \mathrm{kV}$. The value of $10 \mathrm{kV}$ corresponds to $37 \mathrm{Td}$ in the reduced electric field $E / N$ ( $E$ : electric field, $N$ : gas density) of a positive column area using the values $1 \mathrm{~cm}$ gap length and $285 \mathrm{~V}$ cathode sheath drop (Takaki et al., 2000). The electron temperature $T_{e}$ can be estimated from swarm parameters of electrons in nitrogen according to Einstein's well-known equation,

$$
k_{B} T_{e} / e \approx D_{e} / \mu_{e}
$$


where $\mu_{\mathrm{e}}, k_{\mathrm{B}}$ and $D_{\mathrm{e}}$ are drift mobility, Boltzmann constant $\left(1.38 \times 10^{-23} \mathrm{JK}^{-1}\right)$, and the diffusion constant, which can be expressed as a function of $E / N$ (Nakamura, 1987). As a result, the electron temperature is calculated to be $1.3 \mathrm{eV}$, which is much lower than the typical 2 to 5 $\mathrm{eV}$ values of the streamer discharge. The reaction (6) requires higher electron energy larger than $6.1 \mathrm{eV}$. The low electron temperature of the glow phase compared to the streamer discharge is one of the reasons for lower energy yield for NO removal in condition 4 .

\subsection{Influence of oxygen concentration on energy transfer}

Figure 10 shows time-dependence of a discharge current and a voltage between the electrodes for various oxygen concentrations at circuit condition 3; $C=0.48 \mathrm{nF}$ and $L=4.8 \mu \mathrm{H}$ shown in Table 1 . The charging voltage of the primary capacitor is $-20 \mathrm{kV}$. The flow of the gas mixture into the reactor is $4 \mathrm{~L} / \mathrm{min}$. The rise time of the voltage between the electrodes has almost the same value for all oxygen concentrations. As a result, the displacement current which is the first part of the current waveform has the same value at all oxygen concentrations. The discharge current appears around $35 \mathrm{~ns}$ following by the displacement current. The discharge current is quenched earlier by increasing oxygen concentrations. However, the discharge current in all cases is quenched in short time, lower than $100 \mathrm{~ns}$.

Figure 11 shows time-dependence of a discharge current and a voltage between the electrodes for various oxygen concentrations at the circuit condition $4, C=4.2 \mathrm{nF}$ and $L=12.6$ $\mu \mathrm{H}$. The charging voltage and the flow rate of the gas mixture are $-10 \mathrm{kV}$ and $4 \mathrm{~L} / \mathrm{min}$, respectively. In this circuit condition, the displacement current also has the same value at all oxygen concentrations. The discharge current appears at around $80 \mathrm{~ns}$ followed by the displacement current. When the oxygen concentration is lower than $25 \%$, the waveforms of the discharge current and voltage have long decay time compared with the circuit condition 3 as shown in Figure 10. The decay time decreases with increasing oxygen concentrations.

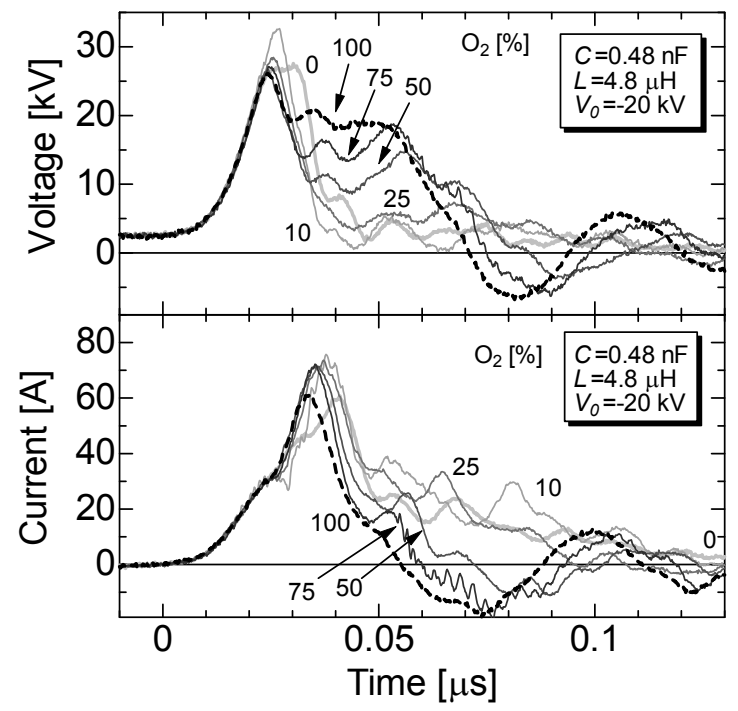

Fig. 10. Time-dependences of applied voltage and discharge current for various oxygen concentrations in the gas mixture at $C=0.48 \mathrm{nF}, L=4.8 \mu \mathrm{H}$ and $V_{0}=-20 \mathrm{kV}$. 


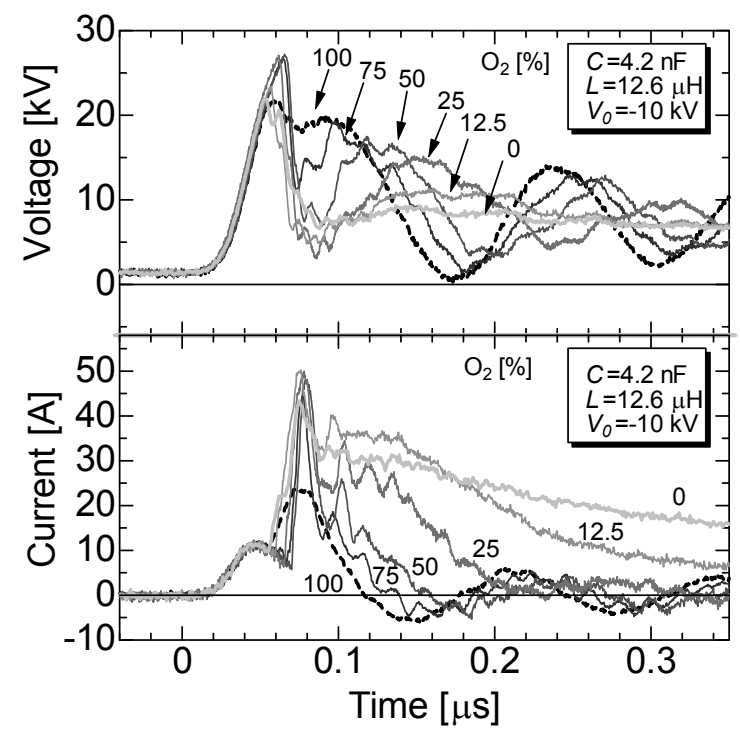

Fig. 11. Time-dependences of applied voltage and discharge current for various oxygen concentrations in the gas mixture at $C=4.2 \mathrm{nF}, L=12.6 \mu \mathrm{H}$ and $V_{0}=-10 \mathrm{kV}$.

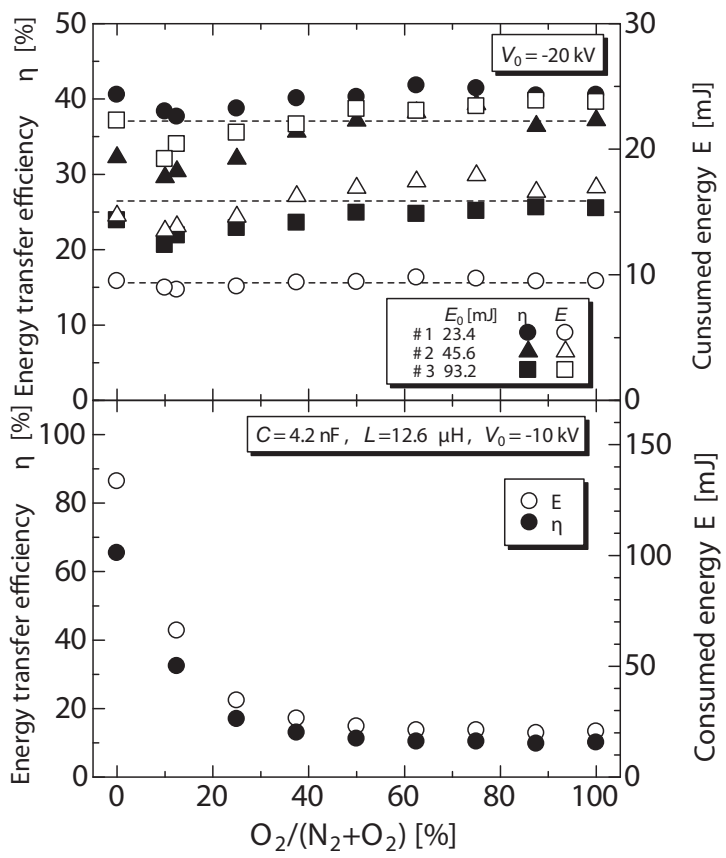

Fig. 12. Energy consumed in the reactor and the energy transfer efficiency from the primary capacitor to the reactor as a function of oxygen concentration for various circuit conditions. 
Figure 12 shows the energy consumed in the reactor and the energy transfer efficiency from the primary capacitor to the reactor as a function of oxygen concentration in the reactor. The consumed energy i.e. the energy transfer efficiency is almost independent of the oxygen concentration in the circuit conditions 1-3. However, the consumed energy drastically decreases with increasing oxygen concentration at lower oxygen concentration than $40 \%$ under the circuit condition 4 . When the oxygen concentration is larger than $40 \%$, the consumed energy shows the constant value and is around $20 \mathrm{~mJ}$. This value is almost the same to that of the circuit condition 3; $C=0.48 \mathrm{nF}$ and $L=4.8 \mu \mathrm{H}$.

\subsection{Influence of oxygen concentration on NO removal efficiency}

The discharge properties in the corona reactor are changed by changing the value of the primary capacitor employed in the IES pulsed power supply and by the gas mixture such as oxygen concentration injected into the corona reactor as mentioned in Sec. 3.3. In this section, NO removal efficiency is described for various oxygen concentrations at two different primary capacitor capacitances to clarify the influence of the carrier gas mixture on NO removal efficiency.

Figure 13 shows the energy consumed in the reactor per one applied voltage pulse, the NO removal and its energy efficiency as a function of oxygen concentration in the NO contained

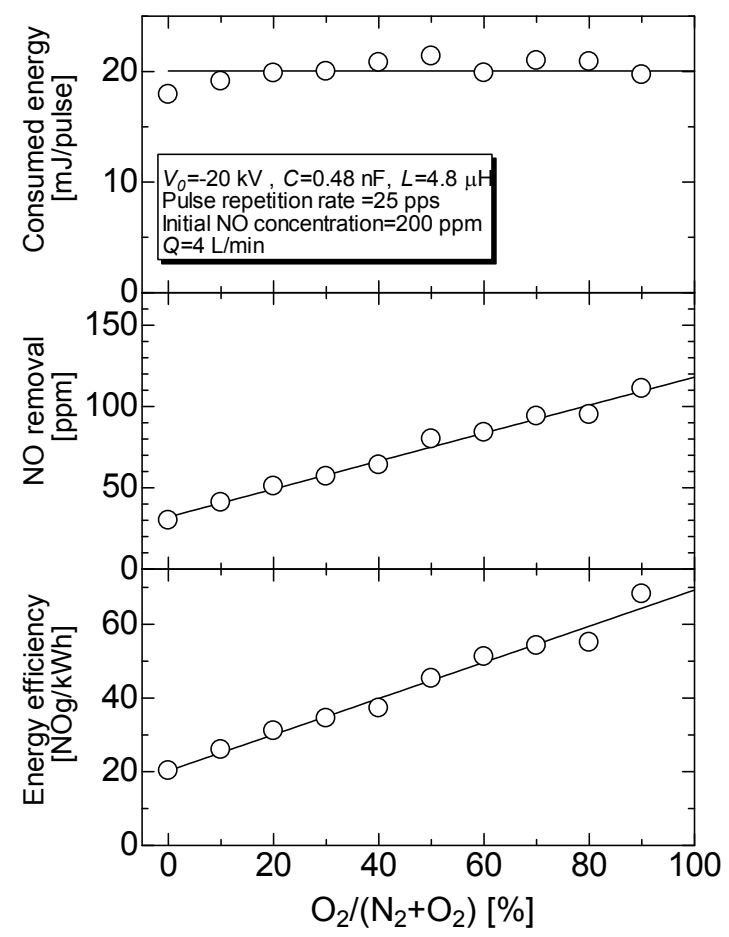

Fig. 13. Consumed energy, NO removal and its energy efficiency as a function of oxygen concentration in the NO contained gas mixture for the circuit condition 3; $C=0.48 \mathrm{nF}$ and $L=4.8 \mu \mathrm{H}$ at $V_{0}=-20 \mathrm{kV}, 25 \mathrm{pps}$ in pulse repetition rate and $4 \mathrm{~L} / \mathrm{min}$ in gas flow rate. 
gas mixture under the circuit condition 3; $C=0.48 \mathrm{nF}$ and $L=4.8 \mu \mathrm{H}$ shown in Table 1 . The charging voltage of the primary capacitor and the pulse repetition rate are $-20 \mathrm{kV}$ and 25 pps, respectively. The gas mixture flow into the reactor is $4 \mathrm{~L} / \mathrm{min}$. The consumed energy per pulse is almost constant and is $20 \mathrm{~mJ}$. NO removal linearly increases from 30 to $110 \mathrm{ppm}$ with increasing oxygen concentration from 0 to $90 \%$. As a result, the energy efficiency for NO removal linearly increases from 20 to $65 \mathrm{~g} / \mathrm{kWh}$, which is calculated using equation (9), with increasing oxygen concentration from 0 to $90 \%$. Generally, NO removal is caused via oxidization process as follows (Gentile and Kushner, 1995, Matzing, 1991):

$$
\begin{gathered}
\mathrm{NO}+\mathrm{O}+\mathrm{M} \rightarrow \mathrm{NO}_{2}+\mathrm{M} ; \quad k_{11}=9.0 \times 10^{-32} \mathrm{~cm}^{6} / \mathrm{s}, \\
\mathrm{NO}+\mathrm{O}_{3} \rightarrow \mathrm{NO}_{2}+\mathrm{O}_{2} ; k_{12}=1.7 \times 10^{-14} \mathrm{~cm}^{6} / \mathrm{s},
\end{gathered}
$$

where $\mathrm{M}$ is the carrier gas concentration i.e. three-body reaction. The ozone and $\mathrm{O}$ radicals are produced via the following reactions:

$$
\begin{gathered}
\mathrm{e}+\mathrm{O}_{2}->\mathrm{O}\left({ }^{3} \mathrm{P}\right)+\mathrm{O}\left({ }^{3} \mathrm{P}\right)+\mathrm{e} ; 6.1 \mathrm{eV} \\
\mathrm{e}+\mathrm{O}_{2}->\mathrm{O}\left({ }^{3} \mathrm{P}\right)+\mathrm{O}\left({ }^{3} \mathrm{D}\right)+\mathrm{e} ; 8.4 \mathrm{eV} \\
\mathrm{O}+\mathrm{O}_{2}+\mathrm{M} \rightarrow \mathrm{O}_{3}+\mathrm{M} ; \quad k_{15}=6.3 \times 10^{-34} \mathrm{~cm}^{6} / \mathrm{s} .
\end{gathered}
$$

The reaction rate of the reactions (13)-(15) increases with increasing oxygen concentration. As a result, the rate of the reactions (11) and (12) increases. This is one of the reasons for the increase of NO removal with oxygen concentration shown in Fig. 13.

Figure 14 shows the energy consumed in the reactor per one applied voltage pulse, NO removal and its energy efficiency as a function of oxygen concentration in the NO contained gas mixture under the circuit condition 4; $C=4.2 \mathrm{nF}$ and $L=12.6 \mu \mathrm{H}$ shown in Table 1 . The charging voltage of the primary capacitor and the pulse repetition rate are $-12 \mathrm{kV}$ and 25 pps, respectively. The gas mixture is flow into the reactor with $4 \mathrm{~L} / \mathrm{min}$. The consumed energy per one pulse decreases from 200 to $36 \mathrm{~mJ}$ with increasing oxygen concentration from 0 to $90 \%$. NO removal is increases from 35 to $150 \mathrm{ppm}$ with increasing oxygen concentration from 0 to $90 \%$. As a result, the energy efficiency for NO removal drastically increases from 2.1 to $51 \mathrm{~g} / \mathrm{kWh}$. In this circuit condition, the streamer-to-glow transition easily occurs in nitrogen rich conditions. However, the streamer-to-glow transition is hard to occur in oxygen rich conditions. As a result, NO can be removed with high energy efficiency in spite of the large capacitance of the primary capacitor.

In general, typical value of oxygen content in diesel engine exhaust gas is $10 \%$, whereas the oxygen content changes in range from 16 to $6 \%$ by a load of the engine (Takaki et al., 2001). The energy efficiencies for NO removal under $10 \%$ oxygen content gas are 26 and 4.9 $\mathrm{g} / \mathrm{kWh}$ for circuit conditions 3 and 4 , respectively. Therefore, it is important to choose circuit parameter adequately in application for $\mathrm{NO}_{x}$ removal from diesel engine exhaust gas.

\subsection{Prevention of glow generation}

The experimental results show that the generation of the glow discharge lowers an energy yield for NO removal when the charge remains in the primary capacitor after opening the switch. The glow discharge is maintained with circuit current from the capacitor through 
the inductor as shown in Fig. 1. If the opening switch is connected with the discharge reactor in series, as shown in Fig. 15, the circuit current is interrupted and the discharge is quenched rapidly. Therefore, the NO removal experiment was carried out using a circuit with SOS diode in series connected to the reactor.

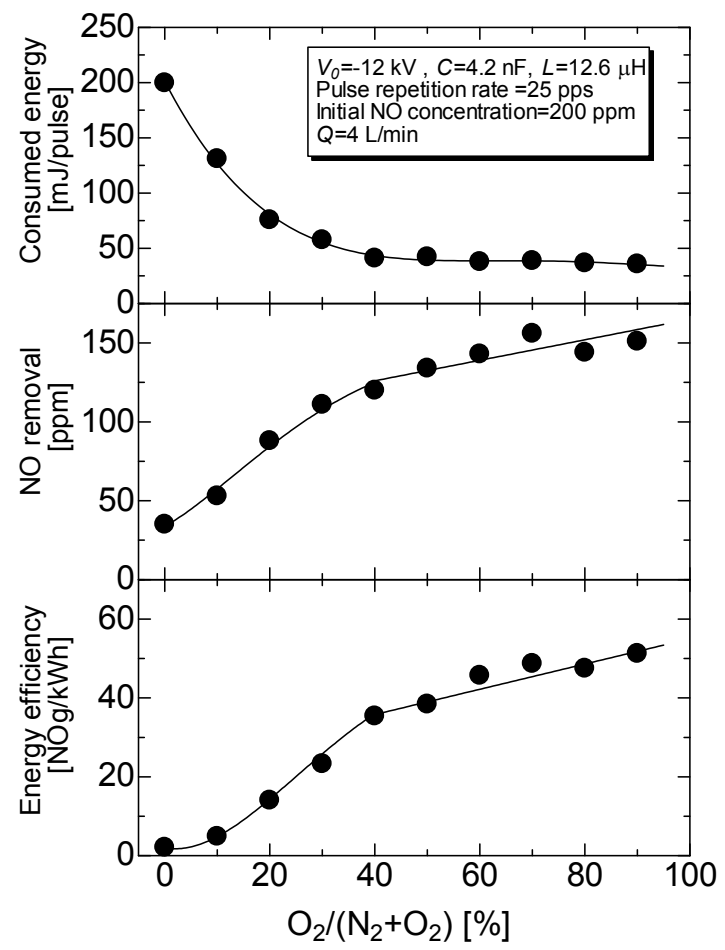

Fig. 14. Consumed energy, NO removal and its energy efficiency as a function of oxygen concentration in the $\mathrm{NO}$ contained gas mixture for the circuit condition; $C=4.2 \mathrm{nF}$ and $L=12.6$ $\mu \mathrm{H}$ at $V_{0}=-12 \mathrm{kV}, 25 \mathrm{pps}$ in pulse repetition rate and $4 \mathrm{~L} / \mathrm{min}$ in gas flow rate.

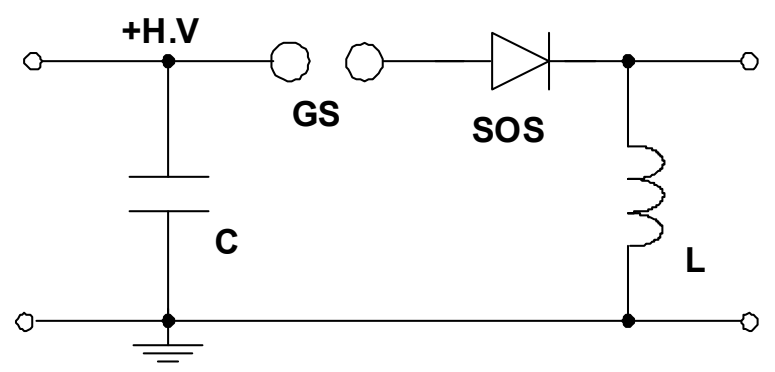

Fig. 15. Pulse power circuit for prevention of glow generation. 
Figure 16 shows the waveforms of the discharge current, voltage between the electrodes, and the energy consumed for different SOS diode positions. The charging voltage of the capacitor is $-12 \mathrm{kV}$. The symbol Cir1 represents the circuit connecting the SOS diode with the reactor in parallel, as shown in Fig. 1, and Cir2 represents the circuit connecting in series, as shown in Fig. 15. In Cir2, the voltage is applied to the reactor before opening the SOS because the inductor is connected to the reactor in parallel. However, the discharge current is almost zero before opening the SOS diode since the charging voltage of $-12 \mathrm{kV}$ is lower than the breakdown voltage of the discharge reactor. After opening the SOS diode, the pulse voltage over $20 \mathrm{kV}$ is applied to the reactor; as a result, the discharge occurs, and the discharge current rapidly increases to $50 \mathrm{~A}$. After that, the discharge current rapidly decreases within 50 ns without glow discharge generation. The energy consumed in the reactor of the Cir2 is about $15 \mathrm{~mJ}$ at $0.6 \mu$ s after opening the SOS diode, which is much less than the $120 \mathrm{~mJ}$ of Cir1.

Figure 17 shows NO removal efficiency and energy efficiency of NO removal as a function of input energy density in the reactor at various circuit conditions. The charging voltage in the primary capacitor is set to $12 \mathrm{kV}$. The LC condition I of $0.70 \mathrm{nF}$ capacitor and $2.5 \mu \mathrm{H}$ inductor $(\pi \sqrt{L C} / 2=66 \mathrm{~ns})$ is employed to generate streamer discharge without a streamerto-glow transition. The LC condition II is the same as condition 4 in which a streamer-toglow transition occurs in Cir1. In the case of the LC condition I, NO removal efficiency for both circuits Cir1 and Cir2 is almost the same. However, in the case of the LC condition II,

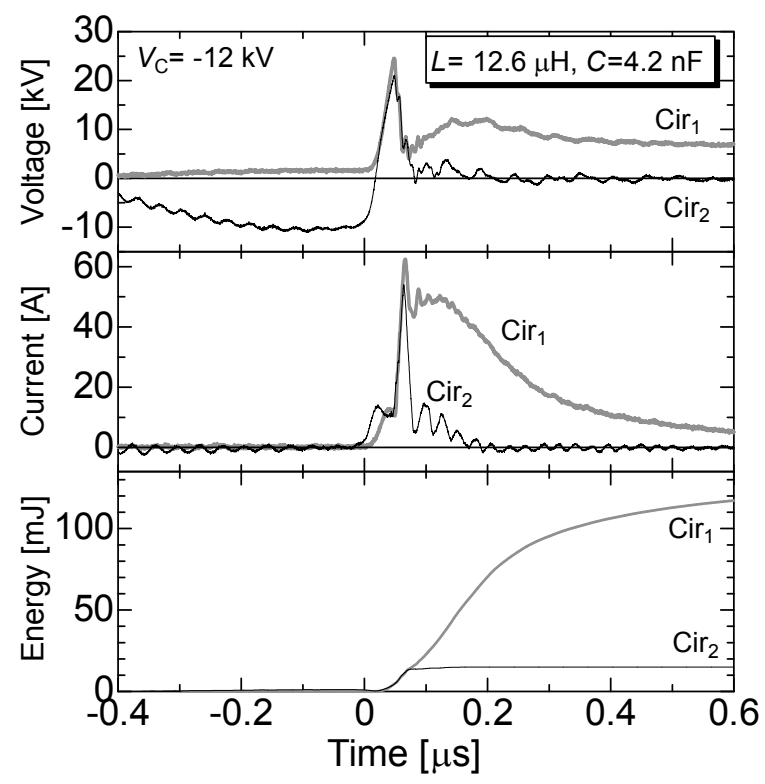

Fig. 16. Waveforms of applied voltage, discharge current, and energy consumed in the reactor for two different circuits. 


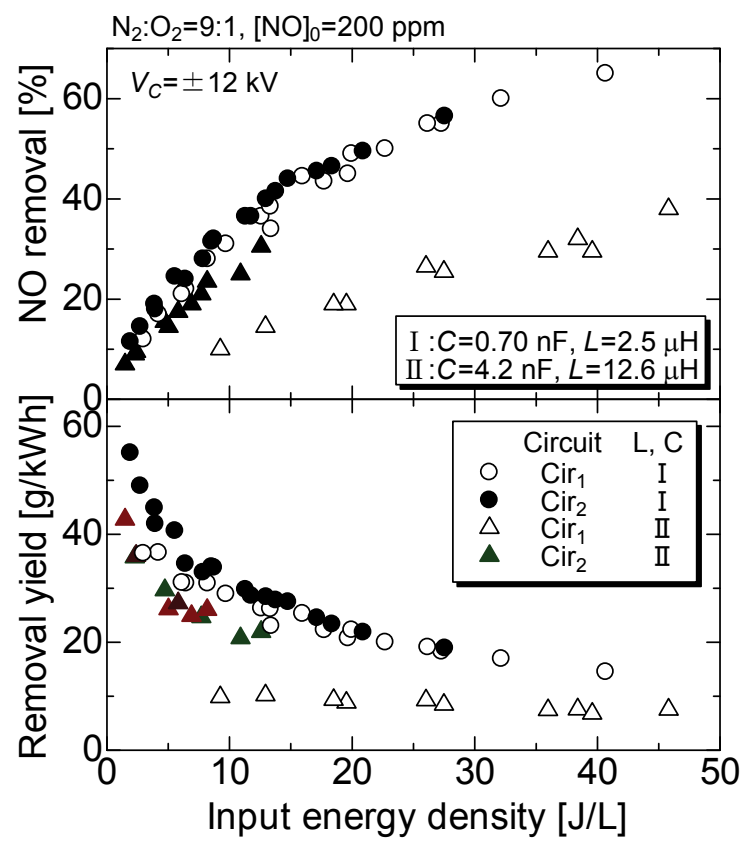

Fig. 17. Dependence of NO removal efficiency and energy efficiency on input energy density for two different circuits.

NO removal efficiency of Cir2 is much higher than that of Cir1. The arrangement of circuit 2, shown in Fig. 15, is effective for prevention of streamer-to-glow transition and to keep high energy efficiency for NO removal.

\section{Conclusion}

The experimental study on NO removal in a pulse corona discharge reactor was carried out to clarify the influence of the streamer-to-glow transition on $\mathrm{NO}$ removal. The inductive energy storage pulsed power generator was employed with a fast recovery diode as a semiconductor opening switch. The pulsed power generator supplied a $30 \mathrm{kV}$ pulse with 300 pps repetition rate. The energy efficiency obtained for NO removal was $25 \mathrm{~g} / \mathrm{kWh}$ at $30 \%$ removal. However, the energy efficiency decreased to $5 \mathrm{~g} / \mathrm{kWh}$ with an increase in capacitance of the primary capacitor from several hundred $\mathrm{pF}$ to several $\mathrm{nF}$. This decrease was caused by the streamer-to-glow transition. The efficiency was affected by oxygen concentration in the gas mixture. The efficiency was successfully improved from 5 to 20 $\mathrm{g} / \mathrm{kWh}$ in the case of several $\mathrm{nF}$-capacitors by changing the connection of the diode and the inductor in the pulsed power circuit. 


\section{References}

Amirov, R.H., Asinovsky, E.I., Samoilov, I.S., and Shepelin, A.V. (1993) 'Oxidation characteristics of nitrogen monoxide by nanosecond pulse corona discharges in a methane combustion flue gas', Plasma Sources Sci. Technol., Vol. 2, pp. 289-295.

Baksht, E. H., Panchenko, A. N., Tarasenko, V. F., Matsunaga, T. and Goto, T. (2002) 'LongPulse-Discharge $\mathrm{XeF}$ and $\mathrm{KrF}$ Lasers Pumped by a Generator with Inductive Energy Storage', Jpn. J. Appl. Phys., Vol. 41, pp. 3701-3703.

Bushlyakov, A. I., Lyubutin, S. K., Ponomarev, A. V., Rukin, S. N., Slovikovsky, B. G., Timoshenkov, S. P. and Tsyranov, S. N. (2006) 'Solid-State SOS-Based Generator Providing a Peak Power of 4 GW', IEEE Trans. Plasma Sci., Vol. 34, pp. 1873-1878.

Cathey, C.D., Tang, T., Shiraishi, T., Urushihara, T., Kuthi, A. and Gundersen, M. A. (2007) 'Nanosecond plasma ignition for improved performance of an internal combustion engine', IEEE Trans. Plasma Sci., Vol. 35, pp. 1664-1668.

Chang, J. S., Lawless, P. A., and Yamamoto, T. (1991) 'Corona discharge processes', IEEE Trans. Plasma Sci., Vol. 19, pp. 1152-1166.

Chang, J.S. (2001) 'Recent development of plasma pollution control technology: a critical review', Sci. E Technol. Adv. Materials, Vol. 2, pp. 571-576.

Clements, J.S., Mizuno, A., Finney, W.C. and Davis, R.H. (1989) 'Combined removal of $\mathrm{SO}_{2}$, NOx, and fly ash from simulated flue gas using pulsed streamer corona', IEEE Trans. Ind. Appl., Vol. 25, pp. 62-69.

Dinelli, G., Civitano, L. and Rea, M. (1990) 'Industrial experiments on pulse corona simultaneous removal of $\mathrm{NO}_{x}$ and $\mathrm{SO}_{2}$ from flue gas', IEEE Trans. Ind. Appl., Vol. 26, pp. 535-541.

Eliasson, B. and Kogelschatz, U. (1991) 'Nonequilibrium volume plasma chemical processing', IEEE Trans. Plasma Sci., Vol. 19, pp. 1063-1077.

Gentile A. C. and Kushner, M. J. (1995) 'Reaction chemistry and optimization of plasma remediation of $\mathrm{N}_{\mathrm{x}} \mathrm{O}_{\mathrm{y}}$ from gas streams', J. Appl. Phys., Vol. 73, pp. 20742085.

Grekhov, I.V. and Mesyats, G.A. (2002) 'Physical basis for high-power semiconductor nanosecond opening switches', IEEE Trans. Plasma Sci., Vol. 28, pp. 1540-1544.

Hackam, R. and Akiyama, H. (2000) 'Air pollution control by electrical discharges', IEEE Trans. Diel. Elect. Insul., Vol. 7, pp. 654-683.

Hill, R. D., Rahmim, I. and Rinker, R. G. (1988) 'Experimental study of the production of $\mathrm{NO}, \mathrm{N}_{2} \mathrm{O}$, and $\mathrm{O}_{3}$ in a simulated atmospheric corona', Ind. Eng. Chem. Res., Vol. 27, pp.1264-1269.

Jiang, W., Nakahiro, K., Yatsui, K., Kim, J. K. and Shimizu, N. (2007) 'Repetitive Pulsed High Voltage Generation Using Inductive Energy Storage with Static-induction Thyristor as Opening Switch', IEEE Trans. Dielectr. Electr. Insul., Vol. 14, pp. 941946.

Lowke, J. J. and Morrow, R. (1995) 'Theoretical analysis of removal of oxides of sulphur and nitrogen in pulsed operation of electrostatic precipitators', IEEE Trans. Plasma Sci., Vol. 23, pp. 661-671. 
Matzing, H. (1991) 'Chemical kinetics of flue gas cleaning by irradiation with electrons', Adv. Chem. Phys., Vol. 80, pp. 315-402.

Nakamura Y. (1987) 'Drift velocity and longitudinal diffusion coefficient of electrons in nitrogen and carbon monoxide', J. Phys. D: Appl. Phys., Vol. 20, pp. 933938.

Namihira, T., Tsukamoto, S., Wang, D., Katsuki, S., Hackam, R., Akiyama, H., Uchida, Y. and Koike, M. (2000) 'Improvement of $\mathrm{NO}_{\mathrm{x}}$ removal efficiency using short-width pulse power', IEEE Trans. Plasma Sci., Vol. 28, pp. 434-442.

Penetrante, B.M., Hsiao, M.C., Merritt, B.T., Vogtlin, G.E. and Wallman, P.H. (1995) 'Comparison of electrical discharge techniques for nonthermal plasma processing of NO in $\mathrm{N}_{2}$ ', IEEE Trans. Plasma Sci., Vol. 23, pp. 679-687.

Robiscoe, R.T., Kadish, A. and Maier II, W.B. (1998) 'A lumped circuit model for transient arc discharge', J. App. Phys., Vol. 64, pp. 4355-4363.

Rukin, S.N. (1999) 'High-power nanosecond pulse generators based on semiconductor opening switches (review) ', Instruments and Experimental Techniques, Vol. 42, pp. 439-467.

Takaki, K. and Akiyama, H. (1992) ‘Development of compact pulsed power generator using inductive energy storage system', Annual Report of Oita National College of Technology, Vol. 28, pp. 19-24 (in Japanese).

Takaki, K., Kitamura, D. and Fujiwara, T. (2000) 'Characteristics of a high-current transient glow discharge in dry air', J. Phys. D: Appl. Phys., Vol. 33, pp. 1369-1375.

Takaki, K. and Fujiwara, T. (2001) 'Multipoint Barrier Discharge Process for Removal of $\mathrm{NO}_{x}$ from Diesel Engine Exhaust', IEEE Trans. Plasma Sci., Vol. 29, pp. 518-523.

Takaki, K., Shimizu, M., Mukaigawa, S. and Fujiwara, T. (2004) 'Effect of electrode shape in dielectric barrier discharge plasma reactor for $\mathrm{NO}_{\mathrm{x}}$ removal', IEEE Trans. Plasma Sci., Vol. 32, pp. 32-38.

Takaki, K., Hosokawa, M., Sasaki, T., Mukaigawa, S. and Fujiwara, T. (2005) 'Production of atmospheric-pressure glow discharge in nitrogen using needle-electrode', Appl. Phys. Lett., Vol. 86, pp. 151501.1-3.

Takaki, K., Kanesawa, K., Mukaigawa, S., Fujiwara, T. and Go, T. (2007) 'Energy Efficiency of Corona Discharge Reactor Driven by Inductive Energy Storage System Pulsed Power Generator', IEEE Trans. Dielectr. Electr. Insul., Vol. 14, pp. 834-845.

Vikharev, A.L., Gorbachev, A.M., Ivanov, O.A., Kolisko, A.L. and Litvak, A.G. (1993) 'Modeling of plasma chemical processes in the artificial ionized layer in the upper atmosphere by the nanosecond corona discharge', Phys. Let. A, Vol. 179, pp. 122126.

Yalandin, M. I., Lyubutin, S. K., Oulmascoulov, M. R., Rukin, S. N., Shpak, V. G., Shunailov, S. A. and Slovikovsky, B. G. (2002) 'High peak power and high average power subnanosecond modulator opening at a repetition frequency of $3.5 \mathrm{kHz}$, IEEE Trans. Plasma Sci., Vol. 30, pp. 1700-1704.

Yankelevich, Y. and Pokryvailo, A. (2002) 'High-power short-pulsed corona: investigation of electrical performance, $\mathrm{SO}_{2}$ removal, and ozone generation', IEEE Trans. Plasma Sci., Vol. 30, pp. 1975-1981. 
Yankelevich, Y., Wolf, M., Baksht, R., Pokryvailo, A., Vinogradov, J., Rivin, B., and Sher, E., A. (2007) 'NOx diesel exhaust treatment using a pulsed corona discharge: the pulse repetition rate effect', Plasma Sources Sci. Technol., Vol. 16, pp. 386-391. 


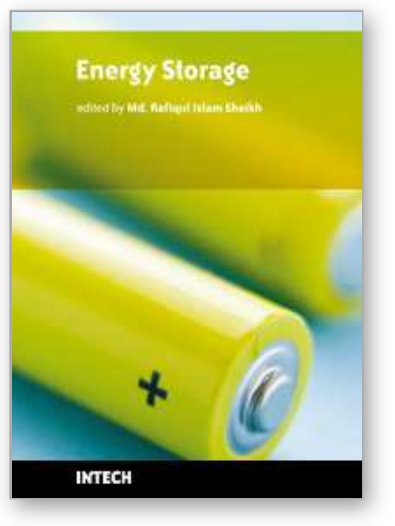

\author{
Energy Storage \\ Edited by Rafiqul Islam Sheikh
}

ISBN 978-953-307-119-0

Hard cover, 142 pages

Publisher Sciyo

Published online 27, September, 2010

Published in print edition September, 2010

Electricity is more versatile in use because it is a highly ordered form of energy that can be converted efficiently into other forms. However, the disadvantage of electricity is that it cannot be easily stored on a large scale. One of the distinctive characteristics of the electric power sector is that the amount of electricity that can be generated is relatively fixed over short periods of time, although demand for electricity fluctuates throughout the day. Almost all electrical energy used today is consumed as it is generated. This poses no hardship in conventional power plants, where the fuel consumption is varied with the load requirements. However, the photovoltaic and wind, being intermittent sources of power, cannot meet the load demand all of the time. Wherever intermittent power sources reach high levels of grid penetration, energy storage becomes one option to provide reliable energy supplies. These devices can help to make renewable energy more smooth and reliable, though the power output cannot be controlled by the grid operators. They can balance micro grids to achieve a good match between generation and load demand, which can further regulate the voltage and frequency. Also, it can significantly improve the load availability, a key requirement for any power system. The energy storage, therefore, is a desired feature to incorporate with renewable power systems, particularly in stand alone power plants. The purpose of this book is twofold. At first, for the interested researcher it shows the importance of different Energy Storage devices, but secondly, and more importantly, it forms a first attempt at dissemination of knowledge to the wider non-expert community who may wish to consider Energy Storage device for specific application. Thus this book will be helpful to provide an indication of the tools necessary for an assessment to be made Energy Storage device more powerful.

\title{
How to reference
}

In order to correctly reference this scholarly work, feel free to copy and paste the following:

Koichi Takaki (2010). Influence of Streamer-to-Glow Transition on NO Removal by Inductive Energy Storage Pulse Generator, Energy Storage, Rafiqul Islam Sheikh (Ed.), ISBN: 978-953-307-119-0, InTech, Available from: http://www.intechopen.com/books/energy-storage/influence-of-streamer-to-glow-transition-mode-on-theno-removal-by-an-inductive-energy-storage-type-

\section{INTECH}

open science | open minds

\author{
InTech Europe \\ University Campus STeP Ri \\ Slavka Krautzeka 83/A
}

\section{InTech China}

Unit 405, Office Block, Hotel Equatorial Shanghai

No.65, Yan An Road (West), Shanghai, 200040, China 
51000 Rijeka, Croatia

Phone: +385 (51) 770447

Fax: +385 (51) 686166

www.intechopen.com
中国上海市延安西路65号上海国际贵都大饭店办公楼 405 单元 Phone: +86-21-62489820

Fax: +86-21-62489821 
(C) 2010 The Author(s). Licensee IntechOpen. This chapter is distributed under the terms of the Creative Commons Attribution-NonCommercialShareAlike-3.0 License, which permits use, distribution and reproduction for non-commercial purposes, provided the original is properly cited and derivative works building on this content are distributed under the same license. 